\title{
Disciplinary discernment: Reading the sky in astronomy education
}

\author{
Urban Eriksson* \\ The National Resource Center for Physics Education, Lund University, Box 118, 22100 Lund, Sweden \\ and LISMA, Department of Mathematics and Science Education, Kristianstad University, \\ 291 88, Kristianstad, Sweden
}

(Received 19 November 2018; published 29 May 2019)

\begin{abstract}
This theoretical paper introduces a new way to view and characterize learning astronomy. It describes a framework, based on results from empirical data, analyzed through standard qualitative research methodology, in which a theoretical model for a vital competency of learning astronomy is proposed: reading the sky, a broad description under with various skills and competencies are included. This model takes into account not only disciplinary knowledge but also disciplinary discernment and extrapolating three dimensionality. Together, these constitute the foundation for the competency referred to as reading the sky. In this paper, these competencies are described and discussed and merged to form a new framework vital for learning astronomy to better match the challenges students face when entering the discipline of astronomy.
\end{abstract}

DOI: 10.1103/PhysRevPhysEducRes.15.010133

\section{INTRODUCTION}

This paper is an extension and synthesis of the previous work done by me and collaborators about the challenges that are related to learning astronomy at the university level. It presents a synthesis based on two publications [1,2] and one thesis [3], leading to the theoretical framework named reading the sky. This includes a set of competencies, where the most important are disciplinary discernment (DD) [2], and extrapolating three dimensionality (E3D) and how it relates to spatial thinking [1]. These two competencies have empirically been found very important, even crucial, for learning astronomy. It is here important to point out to the reader that even though this is a theoretical paper, it is thoroughly grounded in the empirical studies that make the foundation for the work presented here. Also, I must emphasize that the previous empirical work is not summarized in detail but is drawn upon in those places relevant for the arguments presented here.

\section{A. Learning astronomy}

Learning astronomy could be exciting but also challenging and demanding for many students. Over the years, many papers have been published describing various difficulties students encounter when learning astronomy see, for excellent reviews, Refs. [4,5]. These difficulties often revolve

*urban.eriksson@fysik.lu.se, urban.eriksson@hkr.se

Published by the American Physical Society under the terms of the Creative Commons Attribution 4.0 International license. Further distribution of this work must maintain attribution to the author(s) and the published article's title, journal citation, and DOI. around astronomical concepts that in astronomy courses are being presented using a multitude of different disciplinaryspecific semiotic resources, including representations, tools, and activities [6]. Also, learning astronomy involves being able to think about these astronomical concepts in three or four dimensions (3D, 4D). Astronomy as a discipline is special in that it builds almost exclusively on observations, but it is not possible to directly access the Universe by one's eyes, except for the Moon, the stars in the night sky, etc. Instead, every bit of information about the Universe is gathered by different tools, i.e., telescopes and detectors, and processed and finally presented using different types of representations. Learning astronomy then becomes learning to handle and interpret these semiotic resources, which can be seen as learning a new language; it has its particular language and "grammar" [7]. Consequently, a novice needs to learn how to read and use all the different disciplinary-specific semiotic resources that constitute the disciplinary discourse of astronomy [6-9]. Moreover, research has shown that multidimensional (MD) thinking of space, or extrapolating three dimensionality from one- or two-dimensional semiotic resources is both very important and very difficult for students to master [1,3,10-13]. These difficulties taken into account makes it challenging for new-to-the-discipline students to learn astronomy, since not only does the student need to learn disciplinary declarative knowledge, but they need to learn to "read" all the different highly specialized disciplinary-specific semiotic resources that astronomers use to communicate within the discipline $[8,9,14-17]$.

\section{BACKGROUND: READING AS A METAPHOR}

Metaphorically, to read something has many meanings and applications, besides the obvious of reading a written 
text. For example, cultural geographers commonly talk about reading the landscape [18-21], ecology educators talk about reading nature [22], and others uses the term reading science to discuss meaning-making and communication from a social semiotic and semantic approach [8]. From a more general perspective, Card, Mackinlay [23] and Kress and van Leeuwen [9] theorize around reading visualizations or images. For the purpose presented here, I draw primarily on the metaphors reading the landscape and reading nature.

For cultural geographers, reading the landscape concerns the ability to "see" the landscape in the kind of disciplinary way that facilitates the generation of insightful understanding. Hence, the usage of the term calls for a disciplinary understanding of the "language" of landscapes [21]. This means that reading the landscape metaphorically symbolizes the interpretation of a given piece of landscape from observations as if one was reading the "text" of cultural geography language. I interpret such use of reading the landscape as an example that vividly captures how disciplinary-specific representations get used to share perceptions, knowledge, and meaning making within the discipline. In cultural geography the landscape is seen as "being always already a representation" [21] (p. 68), which, by virtue, is visually three dimensional in nature. This framing is useful for making the case for the idea of reading the sky. Consider the resemblances between the connotation reading the landscape and reading the sky: both the landscape and the sky need to be observed and to make sense of those observations they need to be read using an appropriate disciplinary language, cf. Refs. [8,24]. ${ }^{1}$ Learning such language is essentially what the educational endeavor is about in any discipline, see, for example, Refs. [25,26]. For example, in cultural geography Wylie [21] says, "reading refers largely to knowledgeable field observations, and where the landscape is a book in the broadest sense" (p. 71, emphasis added). As such, landscapes are representations to cultural geographers that are to be interpreted rather than just described. Since the ability to read a landscape must vary, the interpretations of what is observed must vary: "There is no single, 'right' way to read a landscape" [18] (p. 603). However, cultural geography educational literature offers little guidance on how fluency in reading the landscape can be educationally achieved nor described.

The educational framing for reading nature by Magntorn [22] in ecology education is, however, more developed and I thus find this framework to be a good starting point to establish the framing of reading the sky. Magntorn describes how reading nature involves two important elements: first, discernment, which he defines as being "able to see things in

\footnotetext{
${ }^{1}$ One must here note a significant difference in that everyone can observe the landscape but to observe the sky (except for the Moon, etc.) one needs a telescope or images and other representations; no first-hand inputs are in principle possible.
}

nature and to discern the differences and similarities between objects in nature" [22] (p. 17) and second, discussion, which for him is effective communication using disciplinaryspecific multimodal representations. These two aspects are interconnected with "outdoor experiences" and "theoretical knowledge" regarding, for example, organisms, processes, and abiotic factors. These are thus vital elements for becoming fluent in the disciplinary discourse of ecology (cf. Ref. [6]). Furthermore, Magntorn frames his findings in terms of "competence," which he characterizes in terms of content knowledge and its associated attained proficiency. In so doing, Magntorn proposes a revised structure of observed learning outcomes (SOLO) taxonomy [27,28]. This revision describes different levels of sophistication concerning reading nature from an ecology education perspective. The levels are used to classify students' and teachers' ability to read nature, and to discuss critical aspects for learning to read nature from a phenomenographic point of view [29-31].

The concepts introduced in this background section will now be used as a point of departure for the following, leading to a definition of reading the sky and the analysis of its importance for learning astronomy.

\section{THEORETICAL FRAMEWORK}

In this section the different parts needed to build reading the sky are introduced and discussed. The framework draws on conceptual change, variation theory, social semiotics, and in particular disciplinary discernment.

\section{A. Science learning from a social semiotic perspective}

Science learning has been addressed numerous times in the literature and there are numbers of different approaches to understand learning science. One of these addresses learning as a change of concepts, often referred to as conceptual change; see, for example, Refs. [32-35]. Here, understanding can be seen as a development of (mis-)conceptions into more advanced concepts around some phenomenon, similar to an "evolution towards increasingly complex concepts that results from a repeated process of integrations, some of which entail new differentiations" [36] (p. 4). For conceptual change to take place students must replace or reorganize their central concepts [32]. This process usually demands some form of inquiry or observation connected to discernment of new relevant features from irrelevant, or background, features; an approach that is well described by variation theory $[30,31]$. An issue of particular importance in this process is the ability to discern disciplinary affordances by different types of semiotic resources [37,38]. Using this as my point of departure, for conceptual change to take place, communications with others inside the discipline becomes central to learning. This communication involves using all representations, tools, and activities that are central to 
the discipline. This approach is well described by social semiotics [7,14,39], which is the preferred framework that I adopt and develop in this paper. In social semiotics, all "communication in a particular social group is viewed as being realized through the use of semiotic resources. In social semiotics the particular meanings assigned to these semiotic resources are negotiated within the social group itself and they have often developed over an extended period of time" [7] (p. 87). From the science education literature, it is clear that to learn to think like a scientist, students should approach learning a discipline like a scientist, i.e., using a multitude of semiotic resources for problem solving in a disciplinary manner; see, for example, Refs. [7,40-42]. The transit from novice to expert is not easy, but a coordinated use of multiple representations indicates increasing student success in learning science; see, for example, Refs. [6,42,43]. Here, it is important to point out that from a social semiotic perspective it is not a question of what a certain representation is a representation of, but instead what meaning this representation conveys for the discipline and how that meaning is constructed by students [7]. Furthermore, a semiotic resource, or representation, often conveys more than one disciplinary meaning, i.e., such resource has a range of disciplinary meaning potentials, or disciplinary affordances [37,38], for a certain community. However, for a student, many of the disciplinary affordances may be invisible. To learn to think like a scientist, the student needs to become fluent in their use of different resources through a process of repetition, by recursively revisit the same material or resources at an increasing level of detail [44]. Through this process the student learns to discern disciplinary affordances of a particular semiotic resource, hence building "representational competence" $[45,46]$. Taking this perspective, learning astronomy, or any science, "can now be framed as coming to discern the disciplinary affordances of semiotic resources" [47] (p. 20), what is referred to as disciplinary discernment [2]. As such, the educational endeavor of the students become one of discerning disciplinary-specific affordances of semiotic resources and disciplinary-specific relevant aspects of a phenomenon, through the process of experiencing appropriate variation of semiotic resources, to allow discernment of differences and similarities within and between different semiotic resources [48].

When probing the astronomy education research literature, many studies are found addressing (mis-)conceptions amongst university students, see, for example Refs. [4,5, 49-55], while at the same time none is found addressing learning astronomy from a social semiotic perspective. This is my point of departure for this paper; students need to fluently learn to read the disciplinary-specific semiotic resources used by astronomers, to avoid misunderstandings and alternative conceptions to arise or be consolidated, hence learn to think like an astronomy expert.

\section{B. Disciplinary discernment and the anatomy disciplinary discernment (ADD)}

At any time in our daily life, we are exposed to huge amounts of information though our senses, but can only focus on a small portion of this information at a time [56]. The challenge is to know what to focus on and discern and, how to know what is important. Here, I characterize this as discernment in terms of coming to know what to focus on and how to appropriately interpret it for a given context. Becoming competent in any discipline involves a similar process, namely, learning; "what to focus on in a given situation and how to interpret it in an appropriate, disciplinary manner" [2] (p. 168). This involves two concepts, noticing and reflection, which are used to define disciplinary discernment. Noticing is connected to learning by experiencing new things or by new observations that trigger new ideas. In astronomy, this happens mostly through visual perception, by noticing of something from a disciplinary-specific representation $[6,57,58]$. "Our senses provide information to our brain that we process, usually in an unconscious way, and only some of this information comes to our conscious awareness' [2] (p. 168), i.e., to distinguish it from the background. For humans to remember something, we need to mark it in our working memory, and can then use it for different things [57], by taking it back into focal awareness to construct meaning, hence change one's thinking [31]. This meaning-making characterizes the process of learning by discernment. See Ref. [2] for an extended discussion on the relationship between noticing and discernment.

Now, one would think that everyone can notice the same things from a representation. This is not the case, since the noticing depends on one's earlier experiences, background, and disciplinary educational level $[59,60]$. The connection to learning is referred to by Lindgren and Schwartz [61] as the noticing effect: "A characteristic of perceptual learning is the increasing ability to perceive more in a given situation. Experts can notice important subtleties that novices simply do not see...[This] helps explain how people can come to perceive what they previously could not, and how the ability to notice often corresponds to competence in a domain.” (p. 421). This highlights how competent performance in noticing from disciplinary semiotic resources is an important ability when trying to become a disciplinary expert. This is similar to what Goodwin [62] calls professional vision, "which consists of socially organized ways of seeing and understanding events that are answerable to the distinctive interests of a particular social group" (p. 606). A wellknown astronomical example involves estimating of the size of the full moon when it is close to the horizon. Most people would say, from their noticing, that the moon is larger when close to the horizon compared to when it is high in the sky. An astronomy expert would know that this is incorrect and illustrate it by, for example, using a hollow 
tube made by a rolled-up paper that is just a little larger than the size of the moon when seen through the tube, then point it to the moon when close to the horizon and when it is higher in the sky. This cancels the effect of the surroundings and one sees that the Moon is the same size, regardless of the position relative to the horizon. ${ }^{2}$ This example highlights the importance of knowing that to look for, in this case the angular size of the moon, and what not to look at, in this case the horizon. It is thus "essential for learning to notice what is important and what is not important" [61] (p. 426), which only can be done by experiencing appropriate variation [31], in this case by looking at and measuring the angular size of the moon at different locations on the sky while at the same time ignoring the silhouette of the horizon.

However, this does not address what it is that makes the difference between a novice and an expert and how a novice moves from being a novice to becoming an expert or disciplinary insider; here reflection play a crucial role for the process of learning. John Dewey characterized reflection as "active, persistent and careful consideration of any belief or supposed form of knowledge in the light of the grounds that support it and the further conclusions to which it tends, constitutes reflective thought" [63] (p. 9). Adding reflection to noticing then characterizes changes in one's thinking, which correspond to the process of learning. This is a clear extension of Goodwin's professional vision [62] in that it addresses what it is that makes the difference between novice and expert and its connection to learning.

Building on these concepts, Eriksson et al. [2] define disciplinary discernment from semiotic resources as follows:

noticing something, reflecting on it, and constructing new meaning from a disciplinary perspective.

It is thus not ordinary discernment referred to here, or even learning some declarative knowledge, but discernment of disciplinary affordances of semiotic resources. Fredlund, Airey, and Linder [37] argue that "learning then, involves coming to appreciate the disciplinary affordances of representations" (p. 658) or semiotic resources. Disciplinary discernment is thus grounded in a specific disciplinary discourse, community, or culture, and involves reading and employing disciplinary-specific semiotic resources, made up, and negotiated over a long time, by the people involved in that discipline. Consider, for example, an HertzsprungRussell (HR) diagram as a typical astronomy example of this in that it holds very many disciplinary-specific affordances, both present and appresent [64]. Students disciplinary discernment from such representation will most like be limited, compared to astronomy experts [65].

\footnotetext{
${ }^{2}$ See, for example, https://www.skyandtelescope.com/observing/ moon-illusion-confusion11252015/.
}

TABLE I. The hierarchy of the anatomy of disciplinary discernment (ADD). For details, see Eriksson et al. [2].

\begin{tabular}{ll}
\hline \hline $\begin{array}{l}\text { Increasing levels of } \\
\text { discernment }\end{array}$ & $\begin{array}{c}\text { The anatomy of disciplinary } \\
\text { discernment }\end{array}$ \\
& $\begin{array}{l}\text { Disciplinary evaluation } \\
\text { Disciplinary appreciation } \\
\text { Disciplinary explanation } \\
\text { Disciplinary identification }\end{array}$ \\
& Nondisciplinary discernment \\
\hline
\end{tabular}

How, then, can disciplinary discernment be characterized as a developing competency? As one might suspect, growing into a discipline leads to increasingly better disciplinary discernment competency. In an empirical investigation Eriksson et al. [2] found that disciplinary discernment by university students and professors of astronomy could indeed be described by increasing levels, or a hierarchy, of disciplinary discernment when they engage with the same disciplinary semiotic resource (a simulation video of a flythrough of our galaxy). The study revealed large differences in disciplinary discernment in relation to educational level, which led to a disciplinary discernment hierarchy - the anatomy of disciplinary discernment (ADD) - the growing ability to discern disciplinary crucial aspects from a vast array of potential affordances of a given representation, i.e., what to focus on and how to interpret it from a disciplinary perspective.

In Table I, a representation of the ADD is presented. It is constructed by five levels of increasing discernment, where the pre-entry level-nondisciplinary discernmentinvolves discernment that has nothing to do with the discipline, similar to everyday discernment. "The discernment is restricted to participants noticing different disciplinary representations presented..., usually without them being able to identify what it is they see. The participants may signal this by posing a question or wondering about what it is they notice" [2] (p. 172).

The other levels of discernment, described in detail in Ref. [2] and summarized here, refer to increasing disciplinary discernment and are defined as follows:

The first level-disciplinary identification-involves recognition and naming of salient disciplinary objects. "This category represents the first signs of disciplinary discernment, as we define it, related to astronomical phenomena and recognition of astronomical structures. In other words, focusing on parts and distinguishing what these afford from a disciplinary perspective" [2] (p. 173).

The second level-disciplinary explanation-involves connecting and assigning disciplinary meaning to discerned objects, similar to discovering the affordances of the representations. One sees "a shift in the description from the what perspective towards a why perspective" [2] (p. 173). This is recognized as a major step in the 
participants disciplinary discernment in that they "start to use their disciplinary knowledge to try to interpret what they see in terms of astronomical properties and astrophysical processes" [2] (p. 173).

The third level of discernment-disciplinary appreciation - involves the ability to discern and analyze the disciplinary affordances of the representations at all levels, hence acknowledging the value of the affordances of the representations. It thus bringing together all previous categories to generate a more holistic view of a particular aspect, subject, or part of the astronomy discourse, including different representations and how they work together at different levels of detail. "Such ability made it possible for the participants to appreciate the simulation in different ways" [2] (p. 174).

Finally, the forth level-disciplinary evaluationcharacterizes the most advanced disciplinary discernment level found. It involves analyzing and critiquing, both positive and negative, the representations used for intended affordances. This level includes, and goes beyond, all previous levels of disciplinary discernment and hence completes the ADD.

Let me give a few examples from the investigation that Eriksson et al. [2] did, where the respondents were looking at a simulated journey through our galaxy to highlight the different levels in the ADD:

Nondisciplinary discernment level.-Two students (A and B) looked at a passage, where the Milky Way was visible in the background, and were intrigued by what they saw but lacked the disciplinary knowledge to interpret it from a disciplinary perspective:

A: 'I don't know what I see, but it gets brighter and I see horizontal irregularly shaped columns. The horizon is a mixture of dark and bright material, and I have a feeling that there is something bright behind it.'

$B$ : 'What's the yellowish band? The horizon-looking thing. And what's the cloud-looking things in it?' ( $p$. 172).

Their attention is caught by the representation and they start reflecting on what is might be, but have no means to interpret it from their earlier experiences.

Disciplinary identification level.-'In this category, the participants are identifying what it is they notice. [...] In this, we see that many descriptions move from '-What is that?' into '-Oh, that is ...', revealing reflective awareness on sameness and differences [30,31] of the structural components of the Universe and how these are represented" (p. 173). One student participant said

C: I'm travelling through the Milky Way galaxy, towards the stars that makes up the constellation Orion (p. 173).

Clearly, signs of recognition can be seen here. $\mathrm{C}$ could easily recognize and name the salient disciplinary objects.
Disciplinary explanation level.-Here, the discernment could be related to composition (structural aspects or what the different objects are made of), color (in relation to emission, absorption, and/or temperature), or other astrophysical aspects (including processes). For example, two students say

D: [The nebula] 'appears to be red from strong Balmer lines, but I am under the impression that the Orion nebula appears slightly green to the naked eye due to trace amounts of ionised oxygen' ( $p$. 173).

E: ... 'interesting to actually see stars having different colors due to different surface temperature ... reddercooler and bluer-hotter.'

Indeed, the students are now adding disciplinary knowledge to their discernment and tries to explain their discernment. Hence, "the disciplinary affordances of representations are beginning to be 'discovered' by the participants" (p. 174).

Disciplinary appreciation level.-At this level, disciplinary discernment involves the ability to analyze what is seen at all levels of detail, sometimes using different representations, and how it all works together. This reveals a more holistic understanding of the astronomical phenomenon under examination, which makes it possible to appreciate the phenomena and representations in different ways. Students F and G say (p. 174):

F: 'So we were between spiral arms. It seems crowdedlots of stars and gas. It is hard to appreciate the stellar neighborhood when we have talk about the distances to our nearest star at 4.2 light years. That seems very far away, yet looking at this rich neighborhood, on the stellar scale, it is actually very close.'

G: 'When I see that clip I start to think about all the things I have learned during the course. What a nebula is, how stars are born, supernovae, and other concepts that I have learned. This picture is not entirely like other pictures I have seen on this object.'

Even if F and G do not say it aloud, it is clear that the students identify the representations presented for them, have an underlying explanation for them, and combine disciplinary knowledge from different areas, to express or build a holistic appreciation of what the representations are intended to afford.

Disciplinary evaluation level.-Let me illustrate this level with a different example from astronomy. In a conversation between two professional astronomers, discussing stellar evolution in an open cluster, one of the astronomers used a gesture to illustrate the turn-off point in the HR diagram for the particular stellar cluster under discussion. The other astronomer immediately identified this semiotic resource (the gesture) as part of the HR diagram and its meaning potential (disciplinary affordance) for estimating the age of the cluster. Although the second 
astronomer agreed to some extent, she critiqued the gesture (its disciplinary affordances or intended meaning) and suggested, using her hands, a different turn-off point (higher "up"), leading to a younger age for the cluster. This I classify as disciplinary evaluation, since the second astronomer easily could discern the meaning of the particular gesture, even though none of them ever mentioned the HR diagram and the gesture was seen from behind. ${ }^{3}$ For a nondisciplinary spectator, this conversation would most likely be completely incomprehensible. An astronomy student would most likely not be able to know what to look for and discern what was important in this communication and hence not fully understand and follow the discussion.

As the reader might notice the presented ADD carries similarities to other classes of novice-to-expert frameworks presented earlier, but in contrast to them the anatomy of disciplinary discernment offers a more fine-grained description of peoples' discernment competencies in a certain domain, allowing expansion of the idea of professional vision to levels of disciplinary discernment; a potentially useful tool for both teaching and learning astronomy. Also, it may be possible to see some similarities between disciplinary explanation and the Framework for Next Generation Science Standards, and in particular "Practice 6-Constructing Explanations and Designing Solutions" [68] (p. 67) where construction of scientific explanations are addressed. For example, the framework says that by grade 12 students should be able to

Use primary or secondary scientific evidence and models to support or refute an explanatory account of a phenomenon.

Offer causal explanations appropriate to their level of scientific knowledge. (p. 67)

However, the disciplinary explanation level is focusing on how explanations are connected to discernment of semiotic resources per se, by revealing what the student focus on and how it is interpreted from a disciplinary perspective. The above competencies are more related to how to construct explanations using semiotic resources, rather than how a certain semiotic resource is understood.

In Table II I highlight and summarize characteristics, differences and similarities between the proposed ADD framework and other classes of novice-to-expert frameworks.

After introducing disciplinary discernment and the ADD and highlighting it by the above examples, I will now address the next fundamental competency needed for to build reading the sky: Extrapolating three dimensionality.

\footnotetext{
${ }^{3}$ The importance of gestures in communicating disciplinary knowledge in physics and astronomy has recently been recognized by others, for example, Refs. [66] and [67].
}

\section{The multidimensionality hierarchy and extrapolating three dimensionality}

This section concerns the concept of spatial thinking as a particularly important aspect of disciplinary discernment [1]. Therefore, I start by defining what I mean by spatial thinking in an astronomy education context. Spatial thinking is

"the recognition, consideration, and appreciation of the interconnected processes and characteristics among astronomical objects at all scales, dimensions, and time” [3] (p. 118).

Spatial thinking has increasingly been identified as an important competency in different science disciplines $[11,75]$ and astronomy is no different in this respect [1,10,76-78]. Indeed, astronomy as a discipline seems to demand excellence in the ability to extrapolate three dimensionality in one's mind from one- or two-dimensional semiotic resources. Here, I remind the reader that learning astronomy demands learning to interpret and handling all the semiotic resources used to communicate astronomy as a science. However, compared to other sciences, learning astronomy is challenging from two particular aspects. First, the astronomical distances in the Universe offers little, if any, possibility to experience an astronomical object from different directions; consequently, the input to our senses are at best two dimensional. Second, an additional complication is the astronomical distances in itself; most astronomical objects are so distant that they cannot be seen by the naked eye. Consequently, every object and phenomena in the Universe needs representations and it is from these representations that our understanding of the Universe is built. Usually, these representations are one- or two-dimensional to its nature. Following the definitions by Gilbert et al. [79], by one-dimensional (1D), I here refer to text, symbols, and mathematics, whereas two-dimensional (2D) representations could be diagram, graphs, images, etc. Three-dimensional (3D) representations are, for example, gestures, real physical models, or simulations and animations, where one can move around in a virtual reality universe, or use 3D glasses.

It is often taken for granted in astronomy education that students will be able to, in their minds, extrapolate a 3D experience from $1 \mathrm{D}$ and $2 \mathrm{D}$ representations. This is despite the growing body of research indicating that this is often not the case $[1,11,78,80-83]$. For example, Parker and Heywood [82] found that students had great difficulty in moving from 2D representations of the solar system to 3D representations. They concluded that "there is a generic problem of spatial awareness in relating to position in space of the observer and the observed objects." [82] (p. 515). However, by using simulations and animations, where students can manipulate objects and positions, others have found that students learn more effectively about astronomical concepts by letting them becoming "living phenomena 


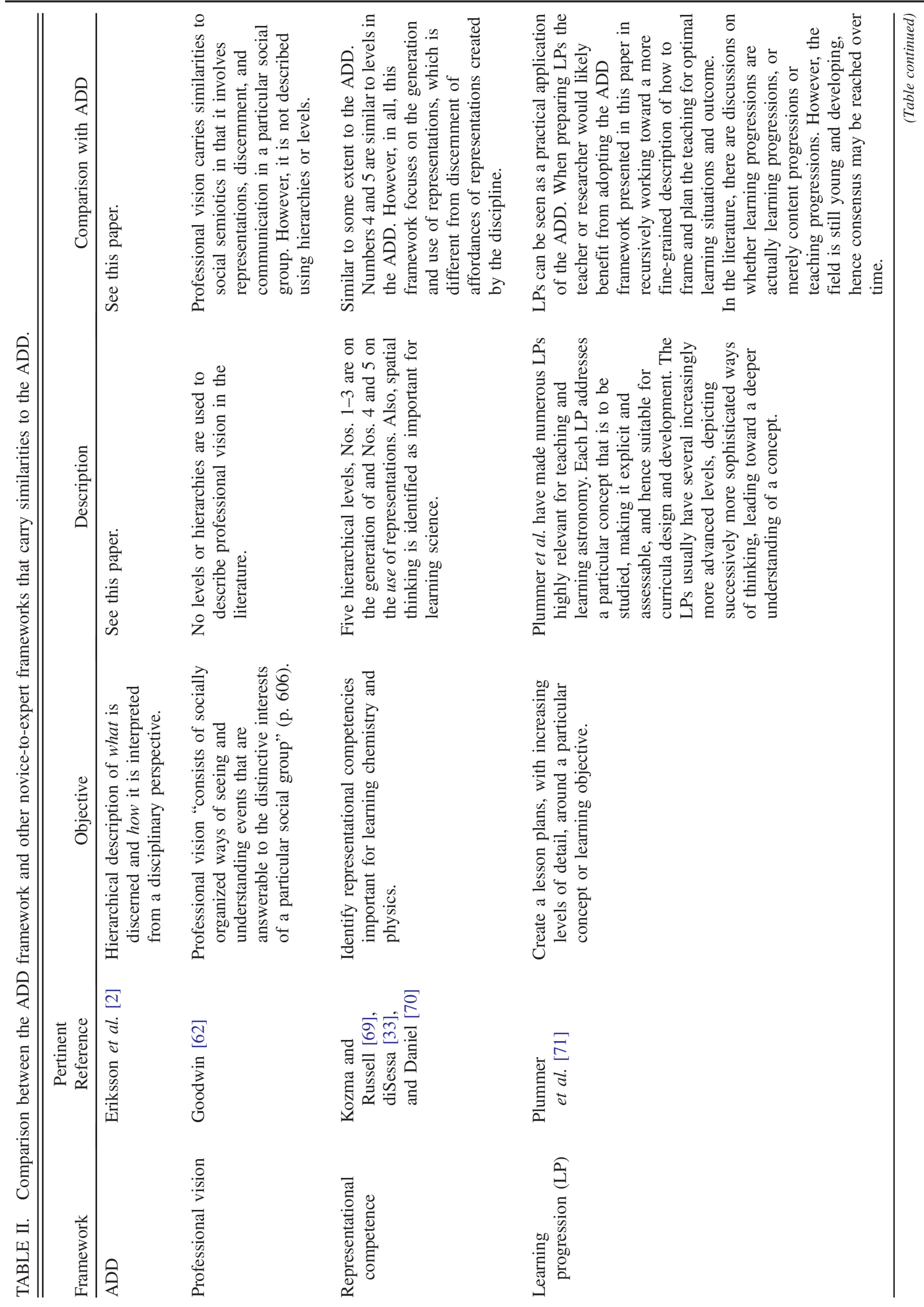




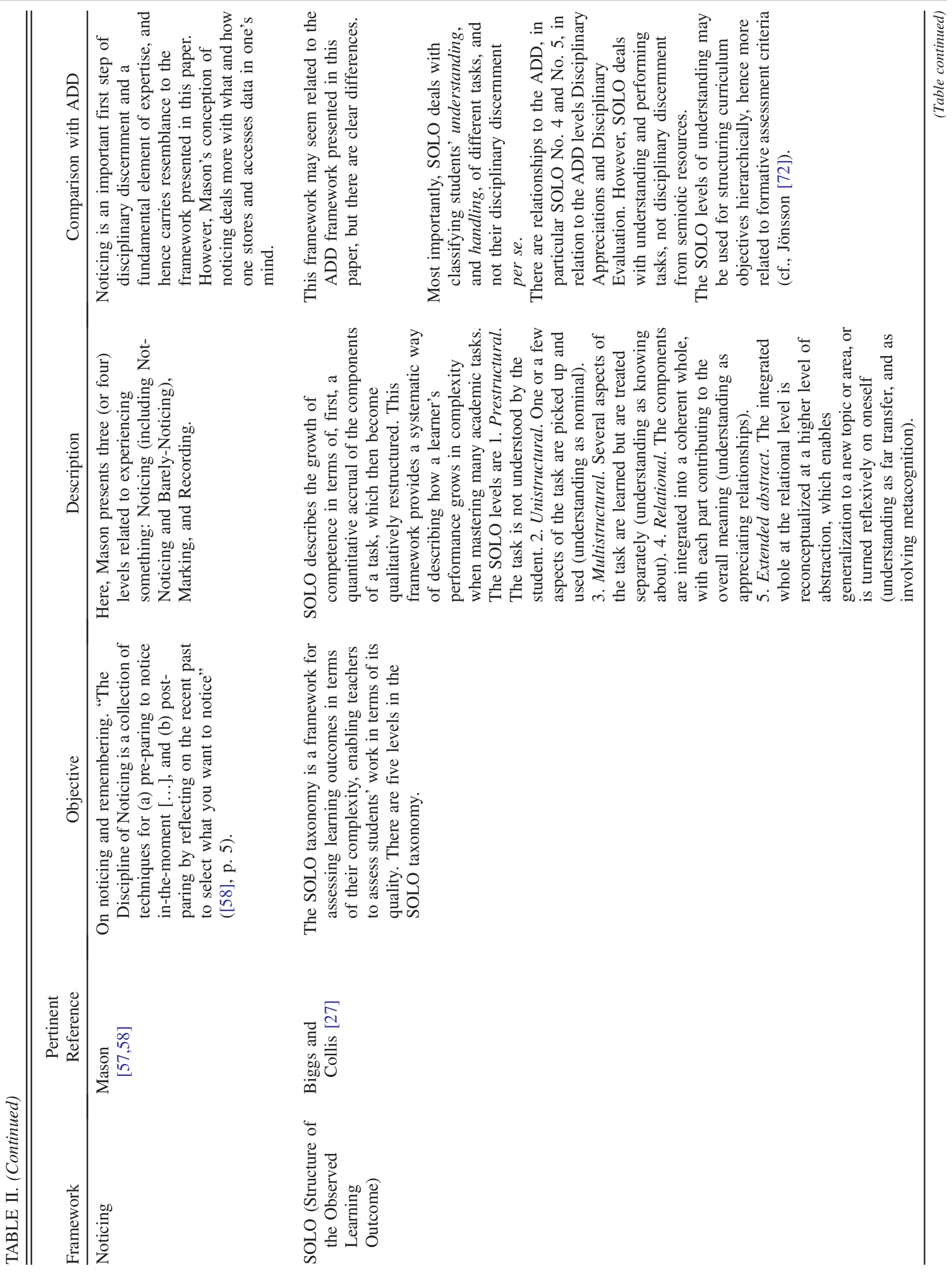




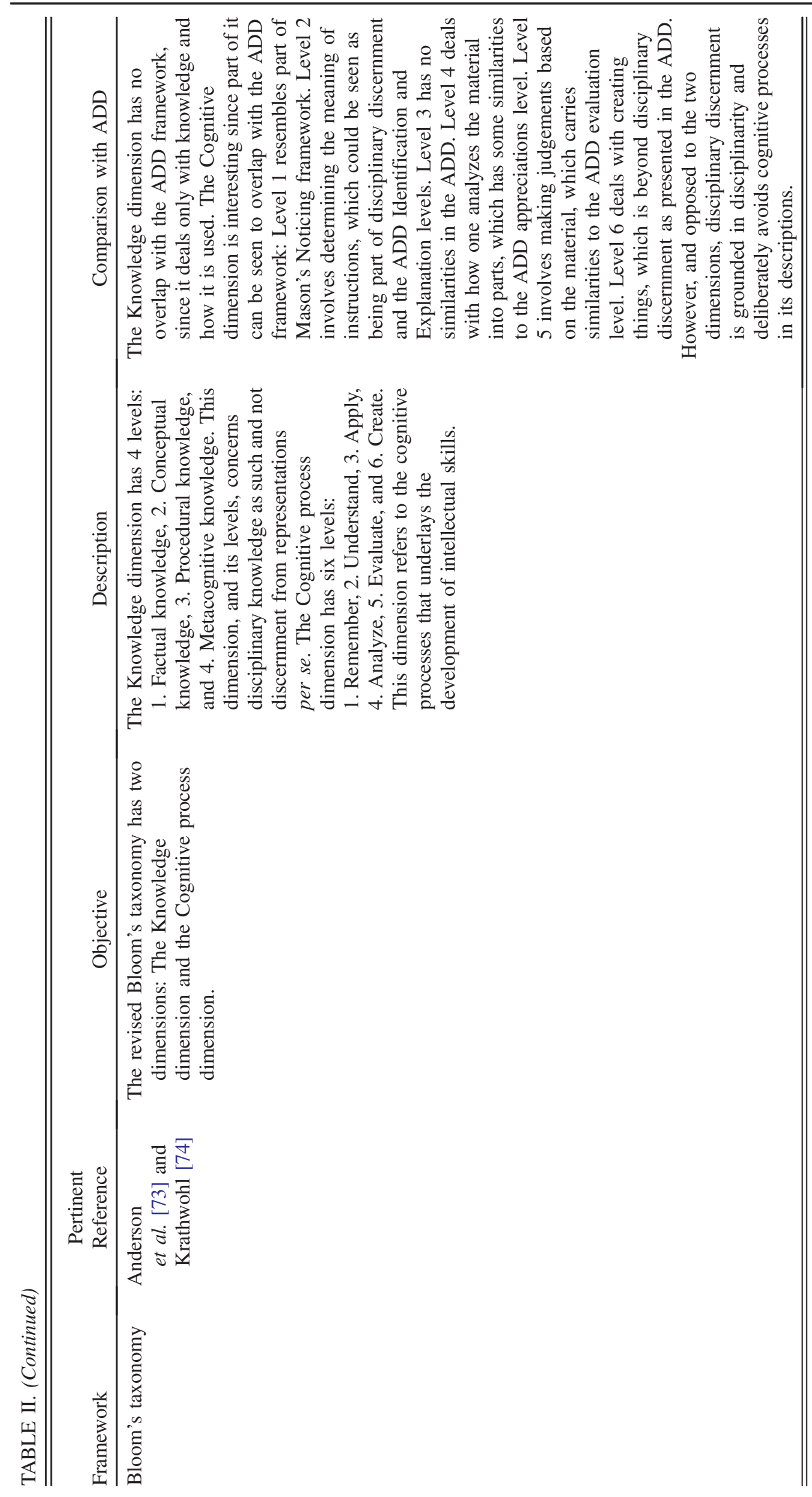




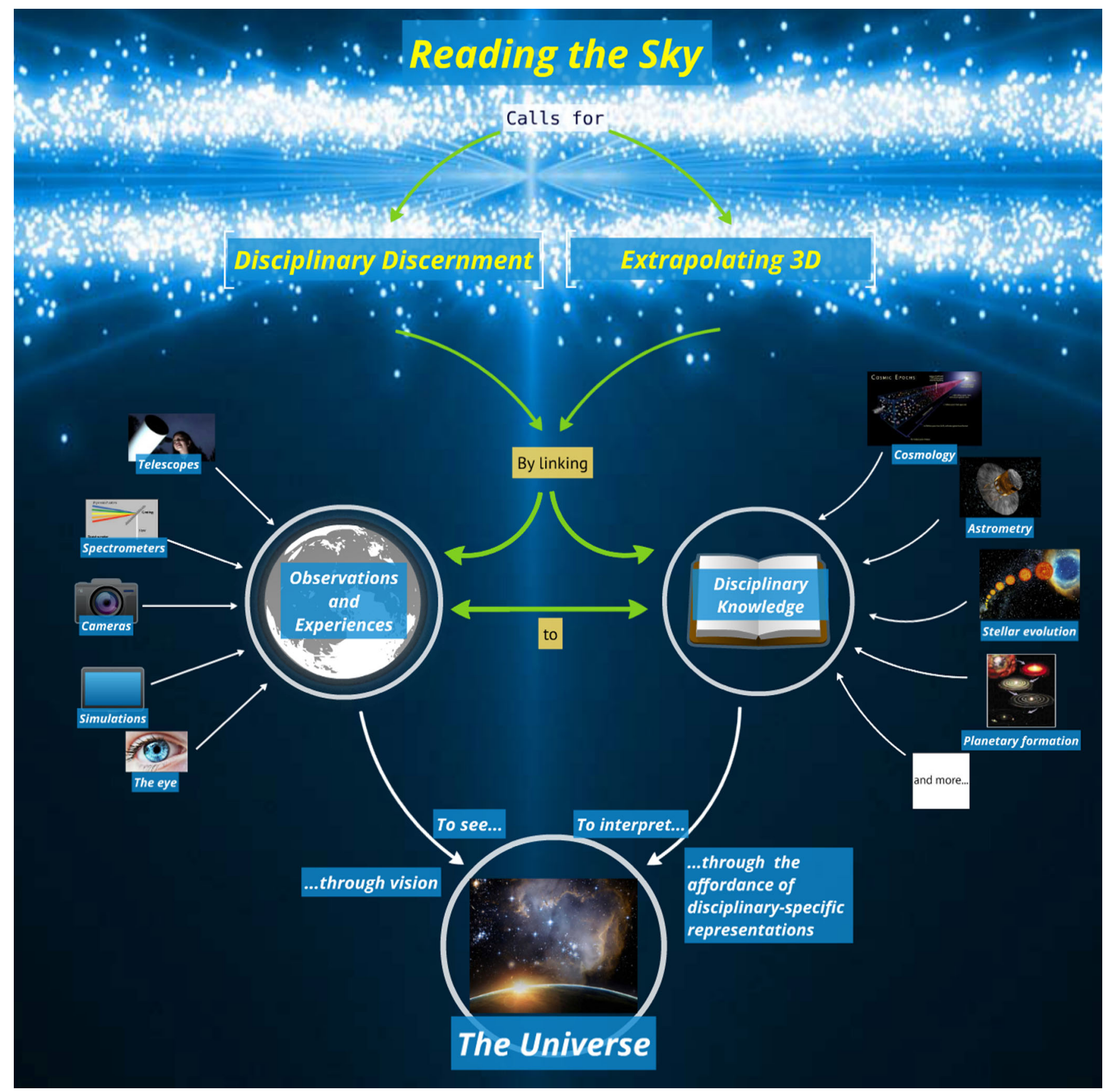

FIG. 1. A graphical representation of how reading the sky is related to disciplinary discernment and extrapolating three dimensionality, by linking observations and experiences to disciplinary knowledge.

that are actualized and not simply realized" [84] (p. 751). This is also highlighted by Plummer [76] in that "Engagement in spatial thinking may be dependent on spatial abilities, but it also builds on prior knowledge and experiences" (p. 4). This highlights the challenge the students face when entering the astronomy discipline; to learn to understand the Universe, they need to learn to think spatially, or develop their competency to extrapolate three dimensionality from one- or two-dimensional inputs, cf. Refs. [76,85]. As an example, the challenges that most students encounter when trying to learn about seasons, or the phases of the Moon, are very well documented across ages and time, and this is only the very first step out into the multidimensional Universe [71,82,86-92]. However, it is not clear from the astronomy education research literature what the required spatial thinking entails and is used for, but experienced astronomy professors repeatedly observe successful students possessing high levels of spatial thinking [10]. The lack of literature in the field is concerning but there is a growing interest from the astronomy education 
research (AER) community to further investigate the connection between success in learning astronomy and extrapolating three dimensionality [76,78,90,93-95]. Here, virtual and augmented reality, and planetaria, are found to offer new possibilities for approaching this [96-103]. However, such resources must be used with considerations; Tversky et al. [104] say, "Like all good things, animation must be used with care" (p. 258).

Extrapolating three dimensionality is thus identified as important in astronomy education, but to what extent do students discern dimensionality aspects in representations? And, is this different from disciplinary discernment mentioned earlier? In an empirical qualitative study on discernment of dimensionality from simulations, Eriksson et al. [1] were able to show how the ability to extrapolate three dimensionality varies by the participating students and professors. The discernment of dimensionality could be categorized into a multidimensionality hierarchy (MDH) of six qualitatively different categories, which could be clustered as a function of 1-3 dimensionality thinking; see Table III and Eriksson et al. [1].

The one-dimensionality disciplinary discernment cluster involves discernment of motion, i.e., the experience of moving forward in terms of direction, speed, acceleration, or rotation. Also, discernment of distance traveled or distance between objects and direction falls under this cluster. The two-dimensionality cluster consists of only discernment of relative size between astronomical objects. For the three-dimensionality cluster, three different types of disciplinary discernment related to dimensionality awareness were identified. These are the following: Emergence of three dimensionality, which involve discerning internal and external structures and details of astronomical objects, reflecting an awareness of depth within an object; growth of three dimensionality, which involves discerning and becoming aware of how astronomical objects and its parts change appearance due to change of perspective, i.e., motion parallax; advanced three dimensionality, which includes all the previous categories but also a more complete awareness of three dimensionality in relation to structures of the Universe at all scales, from the smallest planets and stars to the large scale structure of the Universe [1].

These three-dimensionality discernment categories all incorporate discernment of both width and depth, with reflects 3D awareness of the Universe. For a more detailed description of the categories, see Eriksson et al. [1].

For the arguments presented here, it is discernment related to the three-dimensionality cluster that is most relevant, as it demands the competency to extrapolate in one's mind a 3D awareness of the Universe. Let me illustrate this by a few examples:

A student may start to discern internal structures and details of a nebula, by saying things such as "I see that there are dark absorption nebulae within the Orion nebula, in which stars are formed." Such statements reveal an awareness of nebulae having internal, smaller, structures, which is referred to as microscale three-dimensionality discernment, similar to the emergence of three-dimensionality category. Another student, looking at a simulation where a representation of an open star cluster, the Pleiades, is viewed from a simulated orbit, may say that "From the changing perspective I can see that the stars are located at different places in space and that the familiar look of that cluster only can be seen from one particular direction." This reveals that the student has discerned and become aware of the spatial distribution of stars in the cluster. This is interpreted as an increase in three-dimensionality discernment, compared to the previous category and falls in the growth of three-dimensionality awareness category. Finally, to illustrate this, a professor said: "I thought the movie did a very nice job of capturing a three-dimensional sense of the space around us. The astronomical objects looked fairly three dimensional, and it was nice to see the shape of the constellation Orion change as we approached it." Here, it is clear that the professor discerned and appreciated the 3D representations of astronomical objects at different scales, both the objects themselves, their connections, and the spatial distribution of them, revealing a holistic understanding of the dimensionality of the Universe, similar to the advanced three-dimensionality discernment category.

TABLE III. The multidimensionality (MD) hierarchy. This hierarchy is built by six categories of dimensionality discernment. (Following Eriksson et al. [1]).

\begin{tabular}{lll}
\hline \hline $\begin{array}{l}\text { Categories of dimensionality } \\
\text { discernment }\end{array}$ & $\begin{array}{c}\text { Categories of discernment ordered } \\
\text { hierarchically }\end{array}$ & $\begin{array}{c}\text { Clustering of categories } \\
\text { as function of } \\
1-3 \text { dimensionality }\end{array}$ \\
& $\begin{array}{l}\text { Advanced three dimensionality } \\
\text { Growth of three dimensionality } \\
\text { Emergence of three dimensionality } \\
\text { Relative size awareness }\end{array}$ & Three dimensionality \\
& Distance contemplation & Two dimensionality \\
Baseline category & Motion identification & One dimensionality \\
\hline \hline
\end{tabular}


In what ways are discernment of multidimensionality different from disciplinary discernment? The most important difference concerns disciplinary discernment being grounded in a particular discipline and spatial thinking being a competency that people can develop regardless of discourse belonging, for example using simulation software like Minecraft ${ }^{\mathrm{TM}}$, Universe Sandbox ${ }^{\mathrm{TM}}$, or similar, by moving around in a virtual or augmented reality, or physical model of solar system, etc. When addressing this in an astronomy education context extrapolation of three dimensionality can most easily be promoted, and trained, by using parallax motion of astronomical objects presented in a simulation or animation, or a physical model, which, in principle, does not need to have anything to do with what astronomical object is being represented. Of course, in an astronomy education context disciplinary discernment and extrapolating three dimensionality must be connected and intertwined [3]. For example, an astronomer can easily extrapolate a 3D image in their mind of a rotating spiral galaxy from what is discerned of the disciplinary affordances from a graphical rotation curve (2D) or, how the initial mass function (1D) in combination with an interstellar cloud could lead to various 3D distributions of young stars. An astronomy undergraduate student will not likely be able to make that connection and "see" it like an astronomer would or be able to judge the consequences of the intended meaning of a representation in relation to a 3D object or phenomenon. As such, disciplinary discernment and extrapolating three dimensionality are two sides of the same coin, described by the above presented discernment hierarchies.

Why is spatial thinking then important to train? Being a novice in the astronomy discipline means to learn to understand the Universe, which of course is multidimensional. To build a disciplinary understanding of the Universe, even at the most basic level, thus demands being able to understand it from at least a 3D perspective. This argument is supported by the AER literature that clearly shows that spatial thinking is difficult but at the same time a key factor for success in learning about the Universe $[13,76,78,84,91,93,103,105,106]$.

\section{BUILDING READING THE SKY}

Taking the theories and competencies presented above as my point of departure, I now turn to building and defining what I mean by reading the sky.

\section{A. Defining the sky}

At this point in my discussion I need to further explain what I mean when I refer to the sky [3]:

The sky is the whole Universe at all levels of detail, including all forms of disciplinary-specific representations, and other semiotic resources, describing the
Universe, at all scales, its properties, but also the processes involved in their interaction with the surrounding, at local and large scale, and time.

Taking the previous into account it is clear that there is one major difference between reading the landscape, or nature, and reading the sky; everyone can "see" the landscape, or the environment, but no one can see the whole sky since the astronomical objects (except for the Sun, the moon, and some stars) are too distant and faint for humans to see with their naked eyes. Reading the sky thus calls for being able to read the disciplinary-specific representations that have been created by astronomers to describe and communicate astronomical knowledge. This highlights the size of the challenge at hand; to be able to competently get to "see" the whole Universe, its parts, and how they interact.

Obviously, from an educational point of view, the competency to read the sky must be seen against the educational aims of a given educational context [107] and how it is being assessed [72].

\section{B. Defining reading the sky}

I now propose a definition of reading the sky that brings together the metaphor "reading" with the extrapolation of three dimensionality and disciplinary discernment [3]:

Reading the sky is the competency to discern disciplinary affordances of the sky in order to acquire a holistic, three- and four-dimensional, understanding of the Universe at all levels of scale, dimensions, and detail.

In the definition of reading the sky, I draw on the concepts of reading the landscape [21] and reading nature [22], capturing the varying ability to discern and interpret how disciplinary-specific semiotic resources get used to share perceptions, knowledge, and meaning making within a certain social discipline $[108,109]$. Both of these involve observations and measurements, which have great importance for all of astronomy, but also how these are perceived. As such, reading the sky is grounded in disciplinarity and bridges the gap between the discipline of astronomy and the meaning making that gets constructed from observations and measurements by astronomy learners.

History can provide illustrative examples, e.g., the Danish astronomer Tycho Brahe, who tried to confirm the heliocentric model in the late 16th century by measuring the annual parallax by stars due to the Earth's assumed motion around the Sun. Even though he, at the same time, had both the best predictions from earlier models and the best equipment available at the time, with an uncertainty of only about 15 arcsec, he could not discern any parallax motion $[59,110]$. From his observations, he gathered data on stellar positions and angular distances, made detailed tables, and applied the data to the assumed celestial motions of the Earth (and planets). This indicates that he could critically evaluate the data (the representation 
of stellar positions), similar to critiquing the affordances of the representations in the ADD. At the same time, he must have had a very well-developed special thinking competency, in that he, from the data, could extrapolate three dimensionality and develop an advanced model (at that time), where Earth was at the center of the Universe, with the moon orbiting Earth, the Sun was also orbiting Earth, but all the other planets orbited the Sun. Taking all this into account, Brahe had excellent reading the sky competencies and came to the logical (but erroneous) conclusion that Earth did not move.

Another example can be found in the history of Swedish astronomy; the astronomer Knut Lundmark was involved in the 1930th-century Shapley-Curtis debate about whether the "Andromeda nebula," and other "spiral nebulae," were nearby nebulae or separate galaxies. From his studies in the 1920s of the Andromeda nebula, using measurements made by hand or eye from photographic plates (i.e., graphical representations), of brightness variations of emerging novae or supernovae and comparing them with similar objects with known distances, he came to the conclusion that Andromeda, and also other spiral nebulae, were actually galaxies far away, moving away from us. His method was not very precise and other astronomers at that time could not discern the same things from the data and Lundmark's work was largely disregarded [111]. A few year later, in 1925, Edwin Hubble showed that Andromeda indeed was a galaxy far away, using measurements from Cepheid stars in the Andromeda galaxy.

Analyzing this historical event, I suggest that Lundmark had excellent disciplinary discernment competency, at the highest level of the ADD, since he could not only appreciate the affordances of the representations (photographic plates, tables, graphs, etc.), but also criticize them in a disciplinary manner and from them draw correct conclusions. However, this historical event also highlights the subjective side of science [112], where preconceptions by the involved astronomers concerning the large-scale structure of the Universe came to play a crucial role in how to discern and interpret the new data; Lundmark failed to convince many other astronomers at that time of how to "read" his data and results. From the framework proposed in this paper, this highlights how reading the sky competency vary even for disciplinary experts in their meaning making from observations and measurements.

Reading the sky observations thus include what one can discern using telescopes, by looking at spectra from stellar objects, from images of the sky and astronomical objects, graphs, mathematics, or from any kind of disciplinespecific representations. Such observations normally use the naked eye as a detector. Discernment is constructed from these observations through a meaning-making process that calls for a "fluency" [6] in the disciplinary discourse, which is linked to spatial thinking [1]. Becoming part of the disciplinary discourse of astronomy thus involves being able to fluently read the sky by interpreting, understanding, and using the different semiotic resources, and in particular the representations, that astronomers use to communicate disciplinary knowledge as part of developing a discursive proficiency [22] and identity [60,113,114]. Using this disciplinary discourse perspective, reading the sky calls for the two abilities, disciplinary discernment and extrapolating three dimensionality to be linked to "observations and experiences" and "disciplinary knowledge" in order to be able to "see" through vision, and "interpret" through the affordance of disciplinary-specific representations, the Universe. This is illustrated in Fig. 1.

\section{DISCUSSION}

\section{A. Reading the sky-a competency}

Today, the value of knowledge lies much more in competence performativity and innovation than in simply knowing. As such, education today is increasingly moving towards a competency mindset. Reaching such competency in areas such as science has long been known to be challenging, see, for example, Refs. [115-117], but no one has addressed this from a learning astronomy perspective. Here, learning from disciplinary-specific semiotic resources plays a crucial role, but it is not enough in itself. Moving from everyday conceptions of the world around us to disciplinary interpretations are fraught with pitfalls and problems. Thus, it becomes an important educational consideration to understand what underpins the competency characteristics of the disciplinary learning trajectory. Therefore, and to move the augment forward, a definition of what is meant by competency is needed. For the purpose presented here, I draw on David Dubois' [118] definition of competency as

'those characteristics—knowledge, skills, mindsets, thought patterns, and the like-that when used whether singularly or in various combinations, result in successful performance' ( $p . v)$.

This definition can be contrasted against, e.g., diSessa and Sherin's definition of meta-representational competence (MRC) [35], that is,

'the full range of capabilities that students (and others) have concerning the construction and use of external representations. MRC includes the ability to select, produce and productively use representations but also the abilities to critique and modify representations and even to design completely new representations.' (p. 386)

Although there are overlaps, one can identify a difference in the two definitions that is grounded in the ways that I view learning. From a social semiotic perspective learning takes place as you grow into the discipline and learn how to read the specialized disciplinary-specific representations, 
developed over a long time; that is, learn to understand the inherent meaning of a representation. It is not the construction and use of our own representations that is of central interest, but rather the understanding of what specialized representations mean for the discipline and its use for successful performance and communication within the discipline.

This captures the challenge that students face when entering the astronomy discipline; it is not just standard declarative knowledge that they need to learn to competently understand the Universe, but many other competencies are also needed. In this work, two such competencies important for reading the sky are disciplinary discernment [2] and extrapolating three dimensionality [1]. In this paper, it is argued that becoming part of the discourse of astronomy involves being fluent in read the sky by interpreting, understanding, and using the many different representations that astronomers use to communicate disciplinary knowledge. From the ADD and MD hierarchies [1,2], reading the sky can be viewed as a framework associated with a set of competencies that are highly important for learning astronomy. However, as opposed to the SOLO, or Bloom's taxonomies [73,119-121] (see Table II), the proposed reading the sky framework is grounded in disciplinarity and builds on appreciating how disciplinary knowledge relates to actual astronomical observations of the sky as a function of discerning the disciplinary affordances of representations used in the disciplinary discourse of astronomy. For university students studying astronomy, reading the sky becomes a set of competencies that needs to be striven for; the framing of reading the sky provides a research-informed link between observations from semiotic resources and the meaning making that gets constructed from those observations. Therefore, reading the sky becomes important when addressing learning astronomy, and literature reviews reveal that this has not been addressed or quantified earlier, cf. Refs. [71,76]. In this work, this is done from a disciplinary discernment perspective.

Through my long experiences of teaching physics and astronomy, and carrying out research in both astronomy and astronomy education, I have become fascinated by what students or observers actually believe that they "see"observe, discern, or read-when watching the real sky, visualizations of the Universe, or any other astronomy representations. To competently read the sky is thus a very complex task and so I propose that reading the sky should be acknowledged as a set of competencies. Complementary to disciplinary declarative knowledge, competency in disciplinary discernment and extrapolating three dimensionality, i.e., handling disciplinary knowledge in appropriate ways using disciplinary-specific representations, can be identified as being crucial for reading the sky. Of course, these competencies can only be theoretically separated; in practice they are intertwined with disciplinary knowledge, theory, and practice $[122,123]$. As such, reading the sky opens up a new way to expand learning astronomy through disciplinary discernment by an inclusion of spatial thinking, i.e., extrapolating three dimensionality from one- or two-dimensional input. The discernment of relevant structural components of the Universe and how they interact through different processes, expressed through semiotic resources, involves looking at, reflecting on, and constructing meaning, in relation to the whole of the multidimensional, multiwavelength Universe. This is done through observations and measurements, which have great importance for all of astronomy. Therefore, reading the sky works as a bridge between the discipline of astronomy and astronomy education.

At this point, it is important to recognize that these observations are made and interpreted by human beings; hence they cannot be absolutely objective [112,124] and rely heavily on what a person experiences [125]. In all scientific activity, this phenomenon is well known; for example, the natural scientist Alexander von Humboldt [126] wrote about this in his Aspects of Nature as early as 1849. The dark sky, distant light, colors, odors and fragrance from afar, the silhouette of the horizon, sound, etc., collectively contributes to what gets read by an observer. The challenge lies in only observing the relevant features [127] and the challenge behind that is knowing what these relevant features are and/or how to recognize what these are (consider, for example, the Lundmark, or moon example, given earlier). This becomes increasingly more important in situations where one needs to rely heavily on one's eyes to make observations [59].

\section{B. Reading the sky-highlighting differences between expert and novice}

From an epistemological point of view, all knowledge or well-grounded belief rests on experience; experience that is gained through direct sense perception, in this case, vision, but also audio and tactile. Furthermore, since none of us have identical prior knowledge, different people discern identical things differently [62]. This is not a new idea; it is well known that Socrates used this to argue that our senses cannot access reality in any direct way, or, as Shapere [127] expresses it: "sense-perception is notoriously untrustworthy" (p. 508). At the same time, an image of, for example, a nebula taken by a CCD camera through a telescope, see example in Fig. 2, is also only a representation of the "real" object. This kind of representation gets built on chains of processes and representations that have been coordinated by people, often over a long time period [128]. Such representations have intended meanings, created by someone with a particular purpose, and made up by an enormous number of disciplinary affordances [37]. Typically, when a student looks at a representation of, say, an astronomical object, which normally includes a multitude of disciplinary affordances, the student will only discern a subset of the total disciplinary affordances, set by the discipline 


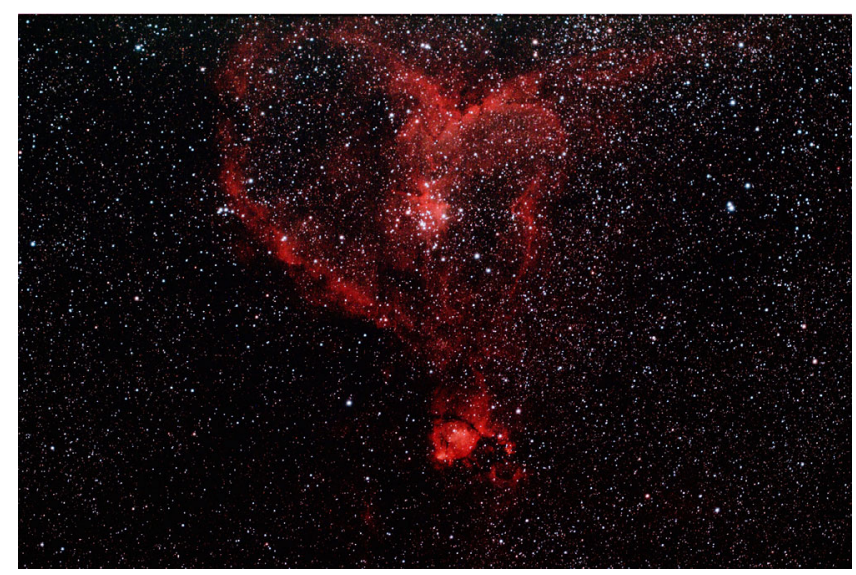

FIG. 2. A CCD image of the "Heart Nebula," IC 1805, taken by a telescope. It is important to be aware that this is only a representation of the real object. Image credit: Jonas Carlsson.

community, of that representation, cf. Ref. [129]. Hence, it is important for professors to be aware that students do not discern the same things from a representation as they do. Thanks to the professors' disciplinary knowledge and educational background, they usually have highly developed disciplinary discernment (cf. professional vision [62]) and are "sensitive to patterns of meaningful information that are not available to novices" [130] (p. 33) in that they can both evaluate and criticize representations in an automatic, unconscious manner [122,131], similar to the highest levels of the ADD and MDH. The students, on the other hand, often focus on the wrong things. Eriksson et al. [2] found that an alarming $43 \%$ of the 1st year undergraduates that participated in their study focused on nondisciplinary things in the presented representations, which highlights the educational challenges at hand.

\section{Reading the sky: A framework also useful for teaching astronomy?}

Reading the sky thus concerns disciplinary discernment of any representation belonging to the astronomy discourse. However, for any student the discerned disciplinary affordances for a particular representation [37] will only constitute a subset of those set by the discipline, cf. Ref. [129]. Hence, there is a potential risk of students missing educationally relevant aspects. Part of the reason for the limitations to what a student can discern from disciplinary representations comes from cognitive load theory see, for example, Ref. [132]. Cognitive load theory portrays the amount of information that can be perceived through vision as being not only limited per se, but also limited by information perceived by our other senses. This becomes a particularly important consideration when choosing to use simulations and animations that attempt to realistically represent aspects of nature as a teaching and learning tool. Here, there is a potential risk of students missing educationally relevant aspects because of cognitive overload [132,133] or by only focusing on the most visually compelling attributes, which might not be relevant for the task at hand [31,134-138]. Astronomy teachers will need to first identify disciplinary relevant aspects of the representations and then help the students by unpacking the disciplinary affordances of the representations, something that has been found to be both difficult and problematic for many students without the help of a teacher $[1,2,128,139]$. Of course, there are many ways to address this, and there are indeed many educational theories that could be useful. Some are more general and some are more practical and I would like to contrast reading the sky against one such theory: Learning progression [76]. The reading the sky framework may seem similar to various learning progression sequences [76], but the proposed framework is not to be seen as such, since learning progressions are usually aimed at describing how one can address a particular topic or concept, by increasing levels of abstraction. The proposed reading the sky framework shall be seen as a general theory for how learning astronomy can be described and quantified through discernment of disciplinary affordances of representations used in the disciplinary discourse. This said, it is reasonable to assume that learning progressions may benefit from using the proposed framework as a starting point and I welcome such efforts by astronomy educators.

Elsewhere [3], I propose a theoretical teaching model, the Spiral of Teaching and Learning, for how to use reading the sky by characterizing what is needed to link extrapolating three dimensionality and disciplinary discernment to disciplinary knowledge as part of informing the optimization of the teaching and learning astronomy. This, however, goes beyond the scope of this paper.

\section{CONCLUSION AND IMPLICATIONS}

The aim of this paper was to introduce and discuss a new framework for learning astronomy: reading the sky. Here, I have argued that becoming part of the discourse of astronomy involves being able to fluently read the sky by discerning, interpreting, understanding, and using the many different semiotic resources that astronomers use to communicate disciplinary knowledge. Using a disciplinary discourse perspective [6], reading the sky calls for the two competencies, disciplinary discernment and extrapolating three dimensionality, to be linked to observations and experiences, and disciplinary knowledge, in order to be able to see through vision, and interpret through the affordance of disciplinaryspecific representations, the Universe. I propose reading the sky to be highly important for learning astronomy and that it goes beyond the concept professional vision [62] in that it holds two important competencies and how these can be described by hierarchies, making them constructive tools when addressing aspects of learning astronomy using semiotic resources, cf. Ref. [35]. As such, reading the sky competencies are vital for efforts aimed at optimizing and improving astronomy education and curricula, by using disciplinary 
discernment from representations as the grounding for learning and in that process help students in their meaning making by tailoring the teaching sequences in terms of crossing category boundaries in the ADD and MDH. I propose that this approach may offer a constructive tool for curricula development across spans of ages of science teaching and learning in schools and at higher education, cf. Ref. [35].

From extensive teaching experience and research, this model, where disciplinary discernment and extrapolating three dimensionality are assumed equally important as disciplinary declarative knowledge, has been found effective for teaching and learning astronomy and physics at the university level $[1,2,10,37,97,139,140]$. It may also be possible that the model would apply to other science subjects as well, in particular where one cannot directly see different phenomena, such as atomic interaction in chemistry, see, for example, Refs. [141-143], or in atomic and particle physics, see, for examples and resources, Ref. [144], where the situations are similar to astronomy in that representations are needed to visualize various phenomena. The proposed theoretical framework should be seen by astronomy professors and educators as offering a new way of thinking when planning teaching to enable students to become part of the disciplinary discourse of astronomy: students need to learn to develop reading the sky competencies, or else they will only see and not discern. The distinction is clear.

\section{ACKNOWLEDGMENTS}

Many thanks to Professor Cedric Linder, Professor Saalih Allie, Professor Ann-Marie Pendrill, and Professor Andreas Redfors for comments and suggestions in improving this paper. Also, thanks to Dr. John Airey and Professor Ed Prather for fruitful discussions around the framework of reading the sky. Finally, thanks to the anonymous reviewers for their very constructive suggestions in how to improve this work.
[1] U. Eriksson et al., Who needs 3D when the Universe is flat?, Sci. Educ. 98, 412 (2014).

[2] U. Eriksson et al., Introducing the anatomy of disciplinary discernment-An example for astronomy, Eur. J. Sci. Math. Educ. 2, 167 (2014).

[3] U. Eriksson, Reading the sky - From starspots to spotting stars, Internet, PhD dissertation, Uppsala, 2014), http:// urn.kb.se/resolve?urn=urn:nbn:se:uu:diva-234636.

[4] J. M. Bailey and T.F. Slater, A review of astronomy education research, Astron. Educ. Rev. 2, 20 (2003).

[5] A. Lelliott and M. Rollnick, Big ideas: A review of astronomy education research 1974-2008, Int. J. Sci. Educ. 32, 1771 (2010).

[6] J. Airey and C. Linder, A disciplinary discourse perspective on university science learning: Achieving fluency in a critical constellation of modes, J. Res. Sci. Teach. 46, 27 (2009).

[7] J. Airey and C. Linder, Social semiotics in university physics education, in Multiple Representations in Physics Education, edited by D. F. Treagust, R. Duit, and H. E. Fischer (Springer International Publishing, Cham, 2017), pp. 95-122.

[8] Reading Science: Critical and Functional Perspectives on Discourses of Science, edited by J. R. Martin and R. Veel (Routledge, London, 1998).

[9] G. Kress and T. van Leeuwen, Reading Images: The Grammar of Visual Design, 2nd ed. (Routledge, Cornwall, 2006).

[10] I. Heyer, S. Slater, and T. Slater, Establishing the empirical relationship between non-science majoring undergraduate learners' spatial thinking skills and their conceptual astronomy knowledge, Revista Latino-Americana de Educação em Astronomia-RELEA 45 (2013).
[11] National Research Council, Learning to Think Spatially: GIS as a Support System in the K-12 Curriculum (National Academies Press, Washington, DC, 2006).

[12] J. D. Plummer, A. Kocareli, and C. Slagle, Learning to explain astronomy across moving frames of reference: Exploring the role of classroom and planetarium-based instructional contexts, Int. J. Sci. Educ. 36, 1083 (2014).

[13] J. H. Mathewson, Visual-spatial thinking: An aspect of science overlooked by educators, Sci. Educ. 83, 33 (1999).

[14] M. A. K. Halliday, Language as Social Semiotic: The Social Interpretation of Language and Meaning (Edward Arnold, London, 1978).

[15] M. A. K. Halliday and J. R. Martin, Writing Science: Literacy and Discursive Power (The Falmer Press, London, 1993).

[16] G. Kress, Multimodality-A Social Semiotic Approach to Contemporary Communication (Routledge, Oxon and New York, 2010).

[17] B. M. Pena and M. J. Gil Quilez, The importance of images in astronomy education, Int. J. Sci. Educ. 23, 1125 (2001).

[18] G. Brierley et al., Reading the landscape: Integrating the theory and practice of geomorphology to develop place-based understandings of river systems, Progr. Phys. Geogr. 37, 601 (2013).

[19] J. Duncan and N. Duncan, (Re)reading the landscape, Environ. Planning Society Space 6, 117 (1988).

[20] N. Duncan and J. Duncan, Doing landscape interpretation, in Handbook of Qualitative Research in Human Geography, edited by D. Delyser, S. Herbert, and S. Aitkin (SAGE, London, 2010), pp. 225-248.

[21] J. Wylie, Landscape (Routledge, Abingdon, 2007). 
[22] O. Magntorn, Reading Nature-Developing Literacy through Teaching (Department of Social and Welfare Studies, Linköping University, Linköping, 2007).

[23] S. K. Card, J. D. Mackinlay, and B. Shneiderman, Readings in Information Visualization: Using Vision to Think, Morgan Kaufmann (Academic press, San Diego, USA, 1999).

[24] S. Ainsworth and N. V. Labeke, Multiple forms of dynamic representation, Learn. Instr. 14, 241 (2004).

[25] R. Veel, The greening of school science: Ecogenesis in secondary classrooms, in Reading Science: Critical and Functional Perspectives on Discourses of Science, edited by J. R. Martin and R. Veel (Routledge, London, 1998).

[26] F. Christie, Science, and apprenticeship: The pedagogic discourse, in Reading Science: Critical and Functional Perspectives on Discourses of Science, edited by J. R. Martin and R. Veel (Routledge, London, 1998).

[27] J. B. Biggs and K.F. Collis, Evaluating the Quality of Learning. The SOLO Taxonomy (Academic Press, New York, 1982).

[28] B. Dart and G. Boulton-Lewis, Teaching and Learning in Higher Education (Stylus Publishing, Herndon, VA, 1998).

[29] F. Marton, Phenomenography-A research approach investigating different understandings of reality, J. Thought 21, 28 (1986); http://www.jstor.org/stable/ 42589189.

[30] F. Marton, Necessary Conditions of Learning (Routledge, New York, 2015).

[31] F. Marton and S. Booth, Learning and Awareness (Routledge, New York, 1997), https://doi.org/10.4324/ 9780203053690.

[32] G. J. Posner, K. A. Strike, P. W. Hewson, and W. A. Gertzog, Accommodation of a scientific conception: Toward a theory of conceptual change, Sci. Educ. 66, 211 (1982).

[33] A. diSessa, Meta-representation: Native competence and targets for instruction, Cognit. Instr. 22, 293 (2004).

[34] A. A. diSessa and B. L. Sherin, What changes in conceptual change?, Int. J. Sci. Educ. 20, 1155 (1998).

[35] A. A. diSessa and B. L. Sherin, Meta-representation: An introduction, J. Math. Behav. 19, 385 (2000).

[36] M. Navarro, Evolutionary Maps: A new model for the analysis of conceptual development, with application to the diurnal cycle, Int. J. Sci. Educ. 36, 1231 (2014).

[37] T. Fredlund, J. Airey, and C. Linder, Exploring the role of physics representations: An illustrative example from students sharing knowledge about refraction, Eur. J. Phys. 33, 657 (2012).

[38] J. Airey et al., On the disciplinary affordances of semiotic resources, in Book of Abstracts: The First Conference of the International Association for Cognitive Semiotics (IACS), 2014 (Lund University, Lund, 2014), pp. 54-55.

[39] T. van Leeuwen, Introducing Social Semiotics (Routledge, London, 2005).

[40] A. Van Heuvelen, Learning to think like a physicist: A review of research-based instructional strategies, Am. J. Phys. 59, 891 (1991).
[41] M. A. McDermott and B. Hand, The impact of embedding multiple modes of representation within writing tasks on high school students' chemistry understanding, Instr. Sci. 41, 217 (2013).

[42] R. Kozma, The material features of multiple representations and their cognitive and social affordances for science understanding, Learn. Instr. 13, 205 (2003).

[43] P. B. Kohl and N. D. Finkelstein, Patterns of multiple representation use by experts and novices during physics problem solving, Phys. Rev. ST Phys. Educ. Res. 4, 010111 (2008).

[44] J.S. Bruner, The Process of Education (Harvard University Press, Cambridge, MA, 1960).

[45] P. B. Kohl and N. D. Finkelstein, Student representational competence and self-assessment when solving physics problems, Phys. Rev. ST Phys. Educ. Res. 1, 010104 (2005).

[46] C. Linder et al., Fostering disciplinary literacy? South African physics lecturers' educational responses to their students' lack of representational competence, African J. Res. Math. Sci. Technol. Educ. 18, 242 (2014).

[47] J. Airey et al., The concept of disciplinary affordance, in The 5th International 360 Conference: Encompassing the Multimodality of Knowledge (Aarhus University, Aarhus, Denmark, 2014).

[48] T. Fredlund, J. Airey, and C. Linder, Enhancing the possibilities for learning: Variation of disciplinaryrelevant aspects in physics representations, Eur. J. Phys. 36, 055001 (2015).

[49] N. F. Comins, Heavenly Errors: Misconceptions About the Real Nature of the Universe (Columbia University Press, New York, 2001).

[50] A. Favia, N. F. Comins, and D. J. Batuski, Taking on astronomy misconceptions isn't easy, Phys. Today 69, No. 8, 74 (2016).

[51] A. Favia et al., A direct examinatin of college students misconceptions in astronomy: A new instrument, J. Rev. Astron. Educ. Outreach 1, A21 (2014).

[52] H. Lee and S. E. Schneider, Using astronomical photographs to investigate misconceptions about galaxies and spectra: Question development for clicker use, Phys. Rev. ST Phys. Educ. Res. 11, 020101 (2015).

[53] B. W. Miller and W. F. Brewer, Misconceptions of astronomical distances, Int. J. Sci. Educ. 32, 1549 (2010).

[54] E. E. Prather, T. F. Slater, and E. G. Offerdahl, Hints of a fundamental misconception in cosmology, Astron. Educ. Rev. 1, 28 (2003).

[55] J. M. Bailey, Astronomy Education Research: Developmental History of the Field and Summary of the Literature (National Academy Press, Washington, DC, 2011).

[56] J. Medina, Brain Rules (Peer Press, Seattle, 2008).

[57] J. Mason, Researching Your Own Practice: The Discipline of Noticing (Routledge Farmer, London, 2002).

[58] J. Mason, Noticing: Roots and branches, in Mathematics Teacher Noticing: Seeing through Teachers' Eyes, edited by M. G. Sherin, V. R. Jacobs, and R. A. Philipp (Routledge, New York, 2011), pp. 35-50.

[59] B. Latour, Visualization and cognition: Thinking with eyes and hands, Knowledge and Society 6, 1 (1986). 
[60] B. Latour and S. Woolgar, Laboratory Life: The Social Construction of Scientific Facts (Princeton University Press, Princeton, NJ, 1979).

[61] R. Lindgren and D. L. Schwartz, Spatial learning and computer simulations in science, Int. J. Sci. Educ. 31, 419 (2009).

[62] C. Goodwin, Professional vision, Am. Anthropologist 96, 606 (1994).

[63] J. Dewey, How We Think, revised ed. (DC Heath, Boston, 1933).

[64] C. Linder, Disciplinary discourse, representation, and appresentation in the teaching and learning of science, Eur. J. Sci. Math. Educ. 1, 43 (2013).

[65] J. Airey and U. Eriksson, What do you see here? Using an analysis of the Hertzsprung-Russell diagram in astronomy to create a survey of disciplinary discernment, in Book of abstracts: The First Conference of the International Association for Cognitive Semiotics (IACS-2014), edited by J. Zlatev and G. Sonesson (Lund University, Lund, Sweden, 2014), pp. 52-53.

[66] B. Gregorcic, G. Planinsic, and E. Etkina, Doing science by waving hands: Talk, symbiotic gesture, and interaction with digital content as resources in student inquiry, Phys. Rev. Phys. Educ. Res. 13, 020104 (2017).

[67] R.E. Scherr, Gesture analysis for physics education researchers, Phys. Rev. ST Phys. Educ. Res. 4, 010101 (2008).

[68] N. R. Council, A Framework for K-12 Science Education: Practices, Crosscutting Concepts, and Core Ideas (The National Academies Press, Washington, DC, 2012), p. 400.

[69] R. Kozma and J. Russell, Students becoming chemists: Developing representational competence, in Visualization in Science Education, edited by J. K. Gilbert (Springer, Dordrecht, 2005), pp. 121-145.

[70] K. L. Daniel, Towards a Framework for Representational Competence in Science Education, Models and Modeling in Science Education, edited by J. K. Gilbert (Springer, New York, 2018), Vol. 11.

[71] J.D. Plummer and L. Maynard, Building a learning progression for celestial motion: An exploration of students' reasoning about the seasons, J. Res. Sci. Teach. 51, 9022014.

[72] A. Jönsson and U. Eriksson, Formative assessment in higher education: An example from astronomy, in Handbook of Formative Assessment in the Disciplines, Vol. 2, edited by Heidi L. Andrade, Randy E. Bennett, and Gregory J. Cizek (Routledge, London, 2019).

[73] L. W. Anderson et al., A Taxonomy of Learning for Teaching: A Revision of Bloom's Taxonomy of Educational Objectives (Addison-Wesley-Longman, New York, 2000).

[74] D. R. Krathwohl, A revision of Bloom's taxonomy: An overview, Theory Pract. 41, 212 (2002).

[75] J. Wai, D. Lubinski, and C. P. Benbow, Spatial ability for STEM domains: Aligning over 50 years of cumulative psychological knowledge solidifies its importance, J. Educ. Psychol. 101, 817 (2009).
[76] J.D. Plummer, Spatial thinking as the dimension of progress in an astronomy learning progression, Studies Sci. Educ. 50, 1 (2014).

[77] J. D. Plummer, A. Kocareli, and C. Slagle, Learning to explain astronomy across moving frames of reference: Exploring the role of classroom and planetarium-based instructional contexts, Int. J. Sci. Educ. 36, 1083 (2014).

[78] M. Cole, C. Cohen, J. Wilhelm, and R. Lindell, Spatial thinking in astronomy education research, Phys. Rev. Phys. Educ. Res. 14, 010139 (2018).

[79] J. K. Gilbert, M. Reiner, and M. B. Nakhleh, Visualization: Theory and Practice in Science Education (Springer, New York, 2008), Vol. 3.

[80] J. A. Hansen et al., The impact of three-dimensional computational modeling on student understanding of astronomy concepts: A qualitative analysis, Int. J. Sci. Educ. 26, 1555 (2004).

[81] J.A. Hansen et al., The impact of three-dimensional computational modeling on student understanding of astronomical concepts: A quantitative analysis, Int. J. Sci. Educ. 26, 1365 (2004).

[82] J. Parker and D. Heywood, The earth and beyond: Developing primary teachers' understanding of basic astronomical events, Int. J. Sci. Educ. 20, 503 (1998).

[83] S. A. Sorby, Educational research in developing 3-d spatial skills for engineering students, Int. J. Sci. Educ. 31, 459 (2009).

[84] S. A. Barab, K. E. Hay, M. Barnett, and T. Keating, Virtual solar system project: Building understanding through model building, J. Res. Sci. Teach. 37, 719 (2000).

[85] S. Schwan and F. Papenmeier, Learning from Animations: From $2 D$ to $3 D$ ?, edited by R. Lowe and R. Ploetzner (Springer, New York, 2017), pp. 31-50.

[86] J. Nussbaum, Students' perception of astronomical concepts. in GIREP Conference 1986, Cosmos: An Educational Challenge (ESA Special Publication, Paris, 1986).

[87] M. Schneps, A Private Universe (Astronomical Society of the Pacific, San Francisco, 1989).

[88] R. Trumper, University students' conceptions of basic astronomy concepts, Phys. Educ. 35, 15 (2000).

[89] K. C. Trundle, R. K. Atwood, and J. E. Christopher, Fourth-grade elementary students' conceptions of standards-based lunar concepts, Int. J. Sci. Educ. 29, 595 (2007).

[90] K. C. Yu et al., Using a digital planetarium for teaching seasons to undergraduates, J. Astron. Earth Sci. Educ. 2, 33 (2015).

[91] Z. Isik-Ercan et al., 'We put on the glasses and Moon comes closer!' Urban Second Graders Exploring the Earth, the Sun and Moon Through 3D Technologies in a Science and Literacy Unit, Int. J. Sci. Educ. 36, 129 (2014).

[92] B. L. Jones, P. P. Lynch, and C. Reesink, Children's conceptions of the earth, sun and moon, Int. J. Sci. Educ. 9, 43 (1987).

[93] D. Heywood, J. Parker, and M. Rowlands, Exploring the visuospatial challenge of learning about day and night and the sun's path, Sci. Educ. 97, 772 (2013). 
[94] National Research Council, Discipline-Based Education Research: Understanding, and Improving Learning in Undergraduate Science, and Engineering, edited by S. R. Singer, N. R. Nielsen, and H. A. Schweingruber (The National Academies Press, Washington, DC, 2012).

[95] K. C. Yu and K. Sahami, in Visuospatial astronomy education in immersive digital planetariums, Communicating Astronomy with the Public (Eugenides, IAU, Athens, Greece, 2007).

[96] K. C. Yu et al., Immersive planetarium visualizations for teaching solar system moon concepts to undergraduates, J. Astron. Earth Sci. Educ. 3, 93 (2016).

[97] K. C. Yu, K. Sahami, and J. Dove, Learning about the scale of the solar system using digital planetarium visualizations, Am. J. Phys. 85, 550 (2017).

[98] C. A. Price et al., Comparing short- and long-term learning effects between stereoscopic and two-dimensional film at a planetarium, Sci. Educ. 99, 1118 (2015).

[99] A.D. Weigel and C.D. Moraitis, Virtual reality astronomy education using AAS WorldWide Telescope and Oculus Rift, in American Astronomical Society Meeting Abstracts, 2017, https://aas.org/meetings/ aas229/.

[100] H.-H. Liou et al., The influences of the 2D image-based augmented reality and virtual reality on student learning, J. Educ. Technol. Soc. 20, 110 (2017); http://www.jstor .org/stable/26196123.

[101] T.F. Slater and C. B. Tatge, Research on Teaching Astronomy in the Planetarium (Springer, New York, 2017).

[102] U. Eriksson, Disciplinary discernment of threedimensionality in virtual learning environments (VLEs)_important for teaching and learning physics and astronomy?, Network Meeting at the Center for Computation in Science Education (Physics Department, Oslo University, Oslo, Norway, 2018).

[103] U. Eriksson, The Outer Universe and the Inner: What is the connection?, International Planetarium Society Conference (IPS2018) (IPS, Toulouse, France, 2018).

[104] B. Tversky, J. B. Morrison, and M. Betrancourt, Animation: Can it facilitate?, International Journal of HumanComputer Studies 57, 247 (2002).

[105] A. Frick, M. A. Hansen, and N. S. Newcombe, Development of mental rotation in 3- to 5-year-old children, Cognit. Dev. 28, 386 (2013).

[106] K. Subramaniam and S. Padalkar, Visualisation and Reasoning in Explaining the Phases of the Moon, Int. J. Sci. Educ. 31, 395 (2009).

[107] U. Eriksson (to be published).

[108] J. Lave and E. Wenger, Situated Learning: Legitimate Peripheral Participation (Cambridge University Press, Cambridge, London, 1991).

[109] S. A. Barab and K. W. Hay, Doing science at the elbows of experts: Issues related to the science apprenticeship camp, J. Res. Sci. Teach. 38, 70 (2001).

[110] C. Roslund, Instrumentinnovatören, in Tycko Brahe Stjärnornas Herre, edited by J. Erlandson (Landskrona kommun, Landskrona, Sweden, 1996), pp. 45-56.

[111] J. Kärnfelt, Allt Mellan Himmel Och Jord: Om Knut Lundmark, Astronomin Och Den Publika
Kunskapsbildningen (Nordic Academic Press, Göteborg, Sweden, 2009).

[112] B. Martin and W. Brouwer, The Subjective Side of Science (University of Alberta, Alberta, 1992).

[113] S. Allie et al., Learning as acquiring a discursive identity through participation in a community: Improving student learning in engineering education, Eur. J. Eng. Educ. 34, 359 (2009).

[114] B. Latour, Science in Action (Harvard University Press, Cambridge, MA, 1987).

[115] P. S. Lottero-Perdue and N. W. Brickhouse, Learning on the job: The acquisition of scientific competence, Sci. Educ. 86, 756 (2002).

[116] E. Etkina, A. Karelina, and M. Ruibal-Villasenor, How long does it take? A study of student acquisition of scientific abilities, Phys. Rev. ST Phys. Educ. Res. 4, 020108 (2008).

[117] S. P. Norris, Defining observational competence, Sci. Educ. 68, 129 (1984).

[118] D. Dubois, The Competency Casebook (International Society for Performance Improvement, Amherst, MA, 1998).

[119] P. W. Airasian et al., A Taxonomy for Learning, Teaching, and Assessing: A Revision of Bloom's Taxonomy of Educational Objectives, edited by L.W. Anderson and D. R. Krathwohl (Addison Wesley, Longmann, NY, 2001).

[120] B. S. Bloom, Taxonomy of Educational Objectives, Vol. 1: Cognitive Domain (McKay, New York, 1956).

[121] D. R. Krathwohl, B. S. Bloom, and B. B. Masia, Taxonomy of educational objectives, Handbook II: Affective Domain (David McKay Company, New York, 1964).

[122] C. Eberbach and K. Crowley, From everyday to scientific observation: How children learn to observe the biologist's world, Rev. Educ. Res. 79, 39 (2009).

[123] U. Eriksson, Reading the sky and the spiral of teaching and learning in astronomy, Proceedings of the ESERA 2015 Conference (ESERA, Helsinki, Finland, 2015).

[124] B. Martin, H. Kass, and W. Brouwer, Authentic science: A diversity of meanings, Sci. Educ. 74, 541 (1990).

[125] W.-M. Roth and A. Jornet, Toward a theory of experience, Sci. Educ. 98, 106 (2014).

[126] A. von Humboldt, Ansichten der Natur: mit wissenschaftlichen Erläuterungen (J. G. Cotta, Stuttgart, 1849).

[127] D. Shapere, The concept of observation in science and philosophy, Philosophy of Science 49, 485 (1982).

[128] T. Fredlund, C. Linder, and J. Airey, A social semiotic approach to identifying critical aspects, Int. J. Lesson Learning Studies 4, 302 (2015).

[129] N. S. Podolefsky and N. D. Finkelstein, How abstract is abstract? Layering meaning in physics, AIP Conf. Proc. 1064, 167 (2008).

[130] J. D. Bransford, A. L. Brown, and R. R. Cocking, How People Learn (National Academy Press, Washington, DC, 2000).

[131] W. Schneider and R. M. Shiffrin, Controlled and automatic human information processing: I. Detection, search, and attention, Psychol. Rev. 84, 1 (1977). 
[132] R. E. Mayer and R. Moreno, Nine ways to reduce cognitive load in multimedia learning, Educ. Psychol. 38, 43 (2003).

[133] R. E. Mayer, Multimedia Learning, 2nd ed. (Cambridge University Press, New York, 2009).

[134] A. Elby, What students' learning of representations tells us about constructivism, J. Math. Behav. 19, 481 (2000).

[135] J. Lemke, Multiplying meaning, in Reading Science: Critical and Functional Perspectives on Discourses of Science, edited by J. R. Martin and R. Veel (Routledge, London, UK, 1998), pp. 87-114.

[136] S. Ainsworth, DeFT: A conceptual framework for considering learning with multiple representations, Learn. Instr. 16, 183 (2006).

[137] S. Ainsworth, The educational value of multiplerepresentations when learning complex scientific concepts, in Visualization: Theory, and Practice in Science Education, edited by J. K. Gilbert, M. Reiner, and M. Nakhleh (Springer, Netherlands 2008), pp. 191-208.

[138] S. Ainsworth, The functions of multiple representations, Comput. Educ. 33, 131 (1999).
[139] T. Fredlund, C. Linder, J. Airey, and A. Linder, Unpacking physics representations: Towards an appreciation of disciplinary affordance, Phys. Rev. ST Phys. Educ. Res. 10, 020129 (2014).

[140] T. Fredlund, C. Linder, and J. Airey, Towards addressing transient learning challenges in undergraduate physics: An example from electrostatics, Eur. J. Phys. 36, 055002 (2015).

[141] R. F. Tasker and R. M. Dalton, Research into practice: Visualisation of the molecular world using animations, Chem. Educ. Res. Pract. 7, 141 (2006).

[142] R. F. Tasker and R. M. Dalton, Visualizing the molecular world-design, evaluation, and use of animations, in Visualization: Theory and Practice in Science Education, edited by J. K. Gilbert, M. Reiner, and M. Nakhleh (Springer, Dordrecht, 2008), pp. 103-131.

[143] M. Stieff, When is a molecule three dimensional? A task-specific role for imagistic reasoning in advanced chemistry, Sci. Educ. 95, 310 (2011).

[144] G. J. Wiener, J. Woithe, A. Brown, and K. Jende, Introducing the LHC in the classroom: An overview of education resources available, Phys. Educ. 51, 035001 (2016). 